\title{
1-Substituted-tricyclo[2.1.0.0 $\left.{ }^{2,5}\right]$ pentan-3-ones. Revisiting the diastereoselectivity
}

\author{
Veejendra K. Yadav, *a Archana Gupta, ${ }^{a}$ Divya Agarwal, ${ }^{a}$ Sachin Srivastava ${ }^{a}$, and \\ Virendra S. Yadava \\ a Department of Chemistry, Indian Institute of Technology, Kanpur-208016, India \\ ${ }^{b}$ Department of Chemistry, University of Lucknow, Lucknow-226001, India \\ E-mail: vijendra@iitk.ac.in
}

\section{This manuscript is dedicated to Dr. A. V. Rama Rao on the occasion of his $70^{\text {th }}$ birth anniversary \\ (received 07 Jul 04; accepted 01 Oct 04; published on the web 08 Oct 04)}

\begin{abstract}
The $\pi$-selectivity of 1 -substituted tricyclo[2.1.0.0 $\left.0^{2,5}\right]$ pentan-3-one is not controlled by the electrostatic effects caused by the polarization of the $\sigma_{\mathrm{C} 1 \mathrm{C} 5}$ bond as suggested recently. The observed selectivity could be explained by the application of the cation complexation approach.
\end{abstract}

Keywords: Tricyclo[2.1.0.0 2,5$]$ pentan-3-one, diastereoselectivity, electrostatic effects, cation complexation approach

\section{Introduction}

Mehta et al. ${ }^{1}$ have recently introduced 1-substituted tricyclo[2.1.0.0 $\left.0^{2,5}\right]$ pentan-3-one as a new probe for the study of $\pi$-selectivity and applied several theoretical models to evaluate their relative performance. The authors investigated the reduction of the substrates 1-3 (Scheme 1) with $\mathrm{NaBH}_{4}$ in $\mathrm{MeOH}$ and found them to favor the anti approach of the hydride ion. The causative factor for the anti preference was suggested to be the polarization of the $\sigma_{\mathrm{C} 1-\mathrm{C} 5}$ bond that was presumed to render C5 positively charged to facilitate the anti attack.

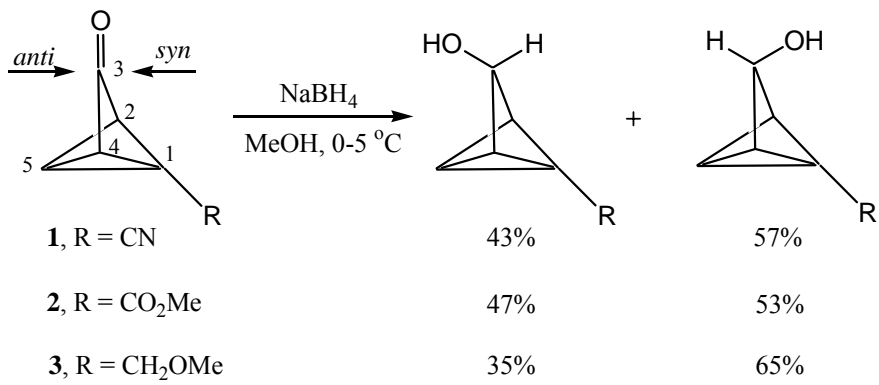

Scheme 1. The $\pi$-selectivity profile of the substrates 1-3. 
Both the observed selectivity and the $\sigma_{\mathrm{C} 1-\mathrm{C} 5}$ polarization argument are truly interesting because, (a) the selectivity profile violated the Cieplak hypothesis ${ }^{2}$ as it will predict the predominantly syn selectivity for the poor electron-donating nature of the $\mathrm{C} 1$-substituent in comparison to the hydrogen atom on $\mathrm{C} 5$, (b) it must clearly be the $\mathrm{C} 1$ that must be rendered more electron-deficient than $\mathrm{C} 5$ and not vice versa, as proposed, for the electron-withdrawing nature of the $\mathrm{C} 1$-substituent, and (c) the central $\sigma_{\mathrm{C} 1-\mathrm{C} 5}$ could be more important than $\sigma_{\mathrm{C} 1-\mathrm{C} 2}$ and $\sigma_{\mathrm{C} 1-\mathrm{C} 4}$ on one side of the carbonyl bridge and $\sigma_{\mathrm{C} 2-\mathrm{C} 5}$ and $\sigma_{\mathrm{C} 4-\mathrm{C} 5}$ on the other side only if the suggested $\sigma_{\mathrm{Cl}-\mathrm{C} 5}$ polarization effects were true and the selectivity had indeed followed the electrostatic control model. The subject therefore deserved attention. We demonstrate herein that the rationale based on the $\sigma_{\mathrm{Cl}-\mathrm{C} 5}$ polarization is erroneous and that the experimental selectivity could very well be explained by the cation complexation approach. ${ }^{3}$

Two major conformers $\mathbf{2 a}$ and $\mathbf{2 b}$ for $\mathbf{2}$ and $\mathbf{3 a}$ and $\mathbf{3 b}$ for $\mathbf{3}$ were envisioned (Figure 1). The ester carbonyl is syn in 2a (dihedral angle $=0^{\circ}$, Figure 3 ) and anti in $\mathbf{2 b}$ (dihedral angle $=180^{\circ}$ ) to $\sigma_{\mathrm{Cl}-\mathrm{C} 5}$. Likewise, the ethereal $\sigma_{\mathrm{C}-\mathrm{O}}$ is syn in 3a (dihedral angle $=55^{\circ}$ ) and anti in $\mathbf{3 b}$ (dihedral angle $\left.=180^{\circ}\right)$ to $\sigma_{\mathrm{Cl}-\mathrm{C} 5}($ Figure 2). The conformers $2 \mathbf{a}$ and $3 \mathbf{a}$ are $0.63 \mathrm{kcal} / \mathrm{mol}$ and $0.18 \mathrm{kcal} / \mathrm{mol}$ more stable than the conformers $\mathbf{2 b}$ and $\mathbf{3 b}$, respectively. ${ }^{4}$ These energy differences are presumably due to the minimization of the dipole interactions in the conformers $2 \mathbf{a}$ and $3 \mathbf{a}$ in comparison to the conformers $\mathbf{2} \mathbf{b}$ and $\mathbf{3} \mathbf{b}$, respectively. Indeed, the calculated dipole moments of 2a and 3a were 2.12 D and 4.18 D and those of $\mathbf{2 b}$ and $\mathbf{3 b}$ were $4.89 \mathrm{D}$ and $4.94 \mathrm{D}$, respectively, at B3LYP/6-31G* level. These conformers were investigated separately to discern the possible conformational effects on the selectivity.

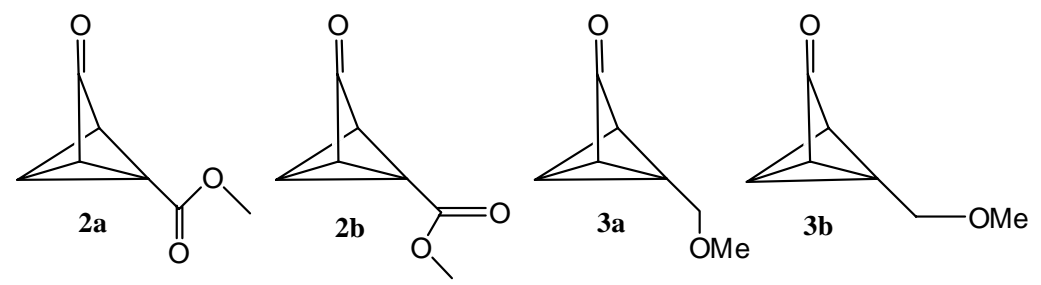

Figure 1. The possible major conformers of 2 and 3.

The NBO charges ${ }^{5}$ on atoms $\mathrm{C} 1, \mathrm{C} 5$, and $\mathrm{C} 3$ are collected in Table 1. C1 is always less electron-rich than $\mathrm{C} 5$ and, thus, the preferred approach of a nucleophile must have been syn for all the substrates if the $\sigma_{\mathrm{Cl}-\mathrm{C} 5}$ polarization and the resultant electrostatic effects were to control the selectivity. However, all the substrates exhibited the opposite anti selectivity. The polarization argument is synonymous with the Houk's electrostatic model ${ }^{6}$ which we have demonstrated earlier not to be a generally valid tool for the $\pi$-facial prediction. ${ }^{7}$ The NBO charge on the carbonyl carbon that remained largely unchanged across 1-3 suggests subtle substituent effects in the ground states. 
Table 1. NBO charges on selected atoms in the substrates 1-3

\begin{tabular}{|c|c|c|c|}
\hline Substrate & \multicolumn{3}{|c|}{ B3LYP/6-31G* Natural Bond Orbital (NBO) charges on } \\
\hline & $\mathrm{C} 1$ & $\mathrm{C} 5$ & $\mathrm{C} 3$ \\
\hline 1 & -0.1507 & -0.1856 & 0.5887 \\
\hline 2a & -0.1361 & -0.1997 & 0.5835 \\
\hline $2 \mathbf{b}$ & -0.1356 & -0.2025 & 0.5847 \\
\hline 3a & -0.0490 & -0.2106 & 0.5818 \\
\hline $3 \mathbf{b}$ & -0.0477 & -0.2170 & 0.5851 \\
\hline
\end{tabular}

The authors have claimed an excellent quantitative performance of the hydride ion model ${ }^{8 \mathrm{a}}$ at the empirical AM1 level over the higher levels of theory through another publication. ${ }^{8 b}$ Energy differences were shown to correlate reasonably well with the observed level of selectivity. Table 2 deals with the application of the hydride model and lists the relative preference for the anti approach of a hydride ion over the corresponding syn approach at the AM1 and B3LYP/6-31G* levels of theory. Irrespective of the conformational orientation of the substituents in $\mathbf{2}$ and $\mathbf{3}$, the AM1 calculations predicted anti approach throughout.

Table 2. Relative energies $(\mathrm{kcal} / \mathrm{mol})$ for the anti-face addition of a hydride ion with respect to the syn-face addition

\begin{tabular}{crr}
\hline AM1 & \multicolumn{2}{c}{ B3LYP/6-31G* } \\
\hline $\mathbf{1}$ & 0.62 & 2.48 \\
2a & 1.03 & 3.23 \\
2b & 1.06 & 1.93 \\
3a & 0.07 & 1.25 \\
3b & 1.73 & 1.80 \\
\hline
\end{tabular}

It is clear from the previously reported energy difference of $0.06(0.07) \mathrm{kcal} / \mathrm{mol}$ for 3 that the previous authors ${ }^{1}$ considered only the conformer 3a. This relatively very small energy difference for 3a in comparison to those for $\mathbf{1}$ and $\mathbf{2}$ does not augur well for the highest anti selectivity observed for 3 . In comparison, the B3LYP/6-31G* calculations predict anti approach to all but 3a. The energy differences at the B3LYP/6-31G* level also do not explain the observed relative level of selectivity. The experimental anti preference of $\mathbf{2}$ is small in comparison to that of $\mathbf{1}$ and even smaller than that of $\mathbf{3}$. The hydride ion model is therefore not suitable for a reliable prediction of the relative level of selectivity. Also, we do not understand why the hydride ion model should predict different approaches at different levels of theory. The case in question is that of 3a which is predicted for anti approach at the AM1 level and for syn approach at the B3LYP/6-31G* level. 

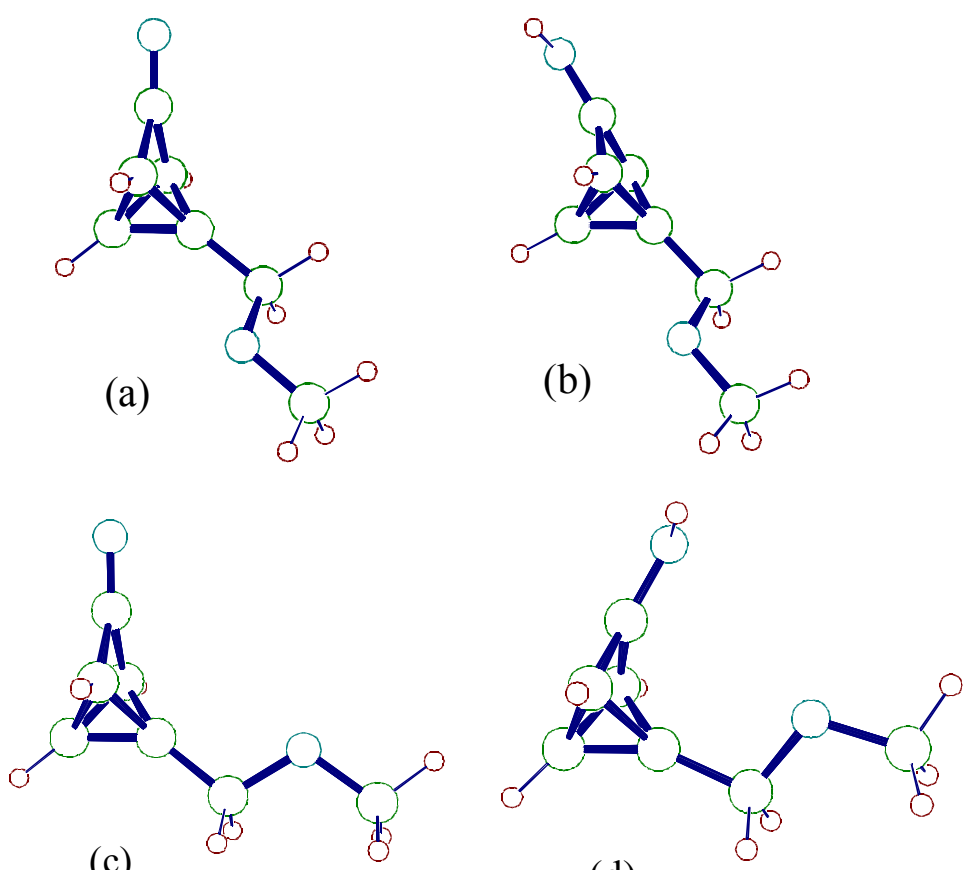

(d)

Figure 2. Calculated B3LYP/6-31G* geometries of $\mathbf{3 a}$, $3 \mathbf{b}$ and their protonated derivatives (a) 3a, (b) 3a- $\mathrm{H}^{+}$, (c) 3b, (d) 3b- $\mathrm{H}^{+}$.

In support of the conformational effects on the selectivities of $\mathbf{3 a}$ and $\mathbf{3 b}$ predicted above at both the AM1 and B3LYP/6-31G* levels, the cation complexation approach ${ }^{3}$ predicts the anti approach to all but 3a. However, since $3 \mathbf{b}-\mathrm{H}^{+}$is more stable (by $1.90 \mathrm{kcal} / \mathrm{mol}$ ) than $\mathbf{3 a}-\mathrm{H}^{+}$at the B3LYP/6-31G* level, ${ }^{9}$ the anti approach must predominate. An enhancement in the dihedral angles $\mathrm{O}-\mathrm{C} 3-\mathrm{C} 4-\mathrm{C} 1$ and $\mathrm{O}-\mathrm{C} 3-\mathrm{C} 2-\mathrm{C} 1$ with a consequent reduction in the dihedral angles O-C3$\mathrm{C} 2-\mathrm{C} 5$ and O-C3-C4-C5 on complexation of the carbonyl oxygen with a cation indicates syn pyramidalization of the carbonyl function and, thus, the syn attack. Conversely, a decrease in the dihedral angles $\mathrm{O}-\mathrm{C} 3-\mathrm{C} 4-\mathrm{C} 1$ and $\mathrm{O}-\mathrm{C} 3-\mathrm{C} 2-\mathrm{C} 1$ with a consequent increase in the dihedral angles $\mathrm{O}-\mathrm{C} 3-\mathrm{C} 2-\mathrm{C} 5$ and $\mathrm{O}-\mathrm{C} 3-\mathrm{C} 4-\mathrm{C} 5$ indicates anti pyramidalization of the carbonyl function and, thus, the anti attack. The calculated geometries of $\mathbf{3 a} / \mathbf{3} \mathbf{a}-\mathrm{H}^{+} / \mathbf{3 b} / \mathbf{3 b}-\mathrm{H}^{+}$are collected in Figure 2.

The low anti selectivity of $\mathbf{2}$ is likely to be due to a competitive coordination of the ester carbonyl as it has a charge distribution very similar to that of the bridge carbonyl. Allowing for this additional complexation of the ester carbonyl with a cation $\left(\mathrm{H}^{+}\right.$in here $),{ }^{3 \mathrm{f}, 7 \mathrm{a}}$ both $\mathbf{2 a}$ and $\mathbf{2 b}$ are predicted for the syn selectivity. Thus, the selectivity of $\mathbf{2}$ is likely to be modulated by the reaction conditions, the nature (Lewis acidity) of the cation present, and the solvent that may act through hydrogen bonding. ${ }^{10}$ Therefore, the facial selectivity of $\mathbf{2}$ is likely to be compromised. It is, therefore, not surprising that 2 exhibits the poorest selectivity of the three substrates. The calculated geometries of $\mathbf{2 a} / \mathbf{2} \mathbf{a}-\mathrm{H}^{+} / \mathbf{2} \mathbf{a}-2 \mathrm{H}^{+}$and $\mathbf{2} \mathbf{b} / \mathbf{2} \mathbf{b}-\mathrm{H}^{+} / \mathbf{2} \mathbf{b}-2 \mathrm{H}^{+}$are collected in Figure 3 . The changes in the important dihedral angles on protonation of 1-3 are collected in Table 3. 

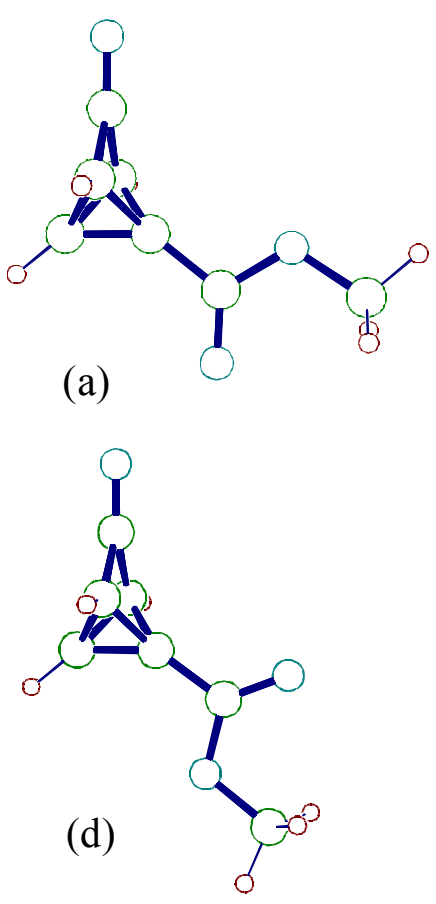

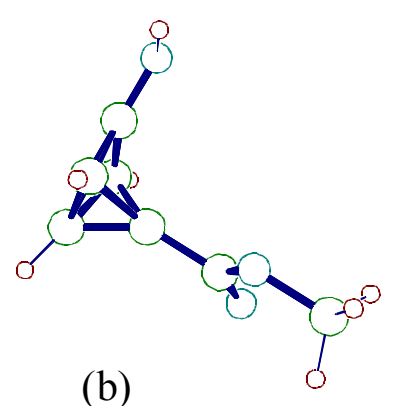

(b)

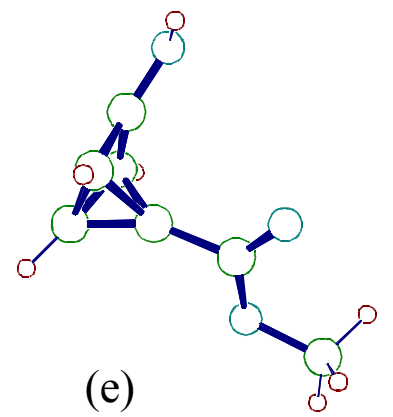

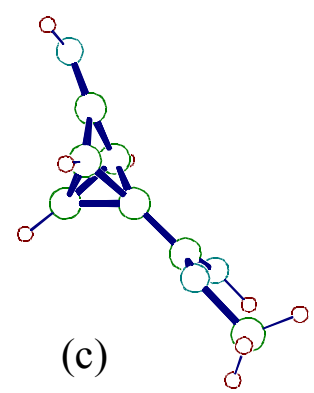

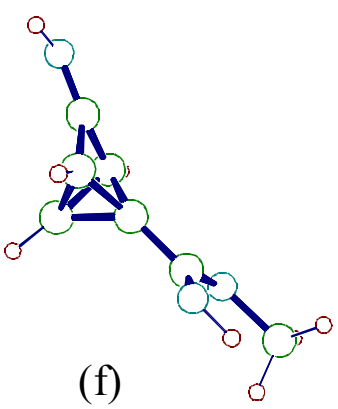

Figure 3. Calculated B3LYP/6-31G* geometries of 2a, 2b and their protonated derivative(a) 2a, (b) $2 \mathbf{a}-\mathrm{H}^{+}$, (c) $\mathbf{2 a}-2 \mathrm{H}^{+}$, (d) $\mathbf{2 b}$, (e) $2 \mathbf{b}-\mathrm{H}^{+}$, (f) $2 \mathbf{b}-2 \mathrm{H}^{+}$.

Table 3. The changes in the dihedral angles on carbonyl protonation at B3LYP/6-31G* level D1 = O-C3-C4-C1, D2 = O-C3-C4-C5, D3 = O-C3-C2-C1, D4 = O-C3-C2-C5

\begin{tabular}{cccccc}
\hline Substrate & $\mathrm{D} 1$ & $\mathrm{D} 2$ & $\mathrm{D} 3$ & $\mathrm{D} 4$ & Energy (Hartrees) \\
\hline $\mathbf{1}$ & 151.1 & 152.8 & 151.1 & 152.8 & -360.2608298 \\
$\mathbf{1}-\mathrm{H}^{+}$ & 121.1 & 175.6 & 123.4 & 177.8 & -360.5675274 \\
$\mathbf{2 a}$ & 151.5 & 153.4 & 151.5 & 153.4 & -495.8929637 \\
$\mathbf{2 a - \mathrm { H } ^ { + }}$ & 119.0 & 173.9 & 121.7 & 176.2 & -496.2219526 \\
$\mathbf{2 a -} 2 \mathrm{H}^{+}$ & 176.7 & 127.2 & 174.4 & 129.6 & -496.4082926 \\
$\mathbf{2 b}$ & 152.6 & 152.2 & 152.6 & 152.2 & -495.8919639 \\
$\mathbf{2 b}-\mathrm{H}^{+}$ & 116.6 & 171.2 & 119.9 & 173.7 & -496.2225057 \\
$\mathbf{2 b -} \mathrm{H}^{+}$ & 176.8 & 127.1 & 174.4 & 129.6 & -496.4084032 \\
3a & 152.0 & 152.8 & 152.0 & 152.7 & -421.8532541 \\
$\mathbf{3 a - H ^ { + }}$ & 172.3 & 118.1 & 174.6 & 120.4 & -422.1895952 \\
3b & 152.9 & 151.6 & 152.9 & 151.6 & -421.8529770 \\
3b- $\mathrm{H}^{+}$ & 120.8 & 174.8 & 123.0 & 176.9 & -422.1926221 \\
\hline
\end{tabular}

Finally, the previous authors have noted restoration of the commonly observed syn preference on the application of several theoretical approaches including the cation complexation approach to endo-4-cyanobicyclo[1.1.1]pentan-2-one, i.e., the species generated from the 
elimination of the $\sigma_{\mathrm{C} 1-\mathrm{C} 5}$ bond from 1 . This result was suggested to support the explanation based on the (erroneous) $\sigma_{\mathrm{C} 1-\mathrm{C} 5}$ polarization $\left(\mathrm{C}^{\delta+} / \mathrm{C}^{\delta-}\right)$. On the very ground that we contemplated a reversed polarization of the $\sigma_{\mathrm{C} 1-\mathrm{C} 5}$ bond $\left(\mathrm{C}^{\delta-} / \mathrm{C}^{\delta+}\right)$ in $1-3, \mathrm{C} 4$ will be expected to be less electron-rich than $\mathrm{C} 5$ in endo-4-cyanobicyclo[1.1.1]pentan-2-one. Indeed, the residual NBO charges on $\mathrm{C} 4$ and $\mathrm{C} 5$ were computed to be, respectively, -0.36 and -0.45 units at B3LYP/6$31 \mathrm{G}^{*}$ level.

In conclusion, the previously reported rationale based on the $\sigma_{\mathrm{C} 1-\mathrm{C} 5}$ polarization to explain the observed $\pi$-selectivities of 1-substituted tricyclo[2.1.0.0 $\left.0^{2,5}\right]$ pentan-3-ones, 1-3, is erroneous. Also, in contrast to the previous claim, the hydride ion model is incapable to predict the relative selectivity level from the differences of the transition state energies at the AM1 level of theory. The cation complexation approach predicts well the selectivities of both the 1-substituted tricyclo[2.1.0.0 $0^{2,5}$ pentan-3-ones and endo-4-cyanobicyclo[1.1.1]pentan-2-one. Additionally, the distance from $\mathrm{C} 1$ to $\mathrm{C} 3$ is about $2.17 \AA$ and the angle $\mathrm{C} 1-\mathrm{C} 3-\mathrm{O}$ is about $162^{\circ}$ in the substrates 13. The $\mathrm{BH}_{4}{ }^{-}$ion has a van der Waals radius of 1.7-2.2 $\AA$ (a diameter of about $4.0 \AA$ ). It seems likely that the preference for the anti attack may, at least in part, be also steric in origin. ${ }^{11}$

\section{Acknowledgements}

The authors thank Department of Science \& Technology, Government of India, for financial support and Professor S. Manoharan of IIT/K for help in the integration of the NBO 5.0 program with Gaussian 98.

\section{References and Notes}

1. Mehta, G.; Singh, S. R.; Priyakumar, U. D.; Sastry, G. N. Tetrahedron Lett. 2003, 44, 3101.

2. (a) Cieplak, A. S. J. Am. Chem. Soc. 1981, 103, 4540. (b) Cieplak, A. S.; Tait, B. D.; Johnson, C. R. J. Am. Chem. Soc. 1989, 111, 8447.

3. (a) Jeyaraj, D. A.; Yadav, A.; Yadav, V. K. Tetrahedron Lett. 1997, 38, 4483. (b) Jeyaraj, D. A.; Yadav, V. K. Tetrahedron Lett. 1997, 38, 6095. (c) Yadav, V. K.; Jeyaraj, D. A. J. Org. Chem. 1998, 63, 3474. (d) Yadav, V. K.; Senthil, G.; Jeyaraj, D. A. Tetrahedron 1999, 55, 14211. (e) Yadav, V. K.; Jeyaraj, D. A.; Balamurugan, R. Tetrahedron 2000, 56, 7581. (f) Yadav, V. K.; Balamurugan, R., J. Chem. Soc., Perkin Trans. 2 2001, 1. (g) Yadav, V. K. J. Org. Chem. 2001, 66, 2501. (h) Yadav, V. K.; Sriramurthy, V. Tetrahedron 2001, 57, 3987.

4. All the computations were performed using Gaussian 98, Revision A.11.1, at B3LYP/631G* level. Frisch, M. J.; Trucks, G. W.; Schlegel, H. B.; Scuseria, G. E.; Robb, M. A.; Cheeseman, J. R.; Zakrzewski, V. G.; Montgomery, Jr., J. A.; Stratmann, R. E.; Burant, J. C.; Dapprich, S.; Millam, J. M.; Daniels, A. D.; Kudin, K. N.; Strain, M. C.; Farkas, O.; Tomasi, J.; Barone, V.; Cossi, M.; Cammi, R.; Mennucci, B.; Pomelli, C.; Adamo, C.; 
Clifford, S.; Ochterski, J.; Petersson, G. A.; Ayala, P. Y.; Cui, Q.; Morokuma, K.; Salvador, P.; Dannenberg, J. J.; Malick, D. K.; Rabuck, A. D.; Raghavachari, K.; Foresman, J. B.; Cioslowski, J.; Ortiz, J. V.; Baboul, A. G.; Stefanov, B. B.; Liu, G.; Liashenko, A.; Piskorz, P.; Komaromi, I.; Gomperts, R.; Martin, R. L.; Fox, D. J.; Keith, T.; Al-Laham, M. A.; Peng, C. Y.; Nanayakkara, A.; Challacombe, M.; Gill, P. M. W.; Johnson, B.; Chen, W.; Wong, M. W.; Andres, J. L.; Gonzalez, C.; Head-Gordon, M.; Replogle, E. S.; Pople, J. A. Gaussian, Inc., Pittsburgh PA, 2001.

5. NBO 5.0. E. D. Glendening, J. K. Badenhoop, A. E. Reed, J. E. Carpenter, J. A. Bohmann, C. M. Morales, and F. Weinhold (Theoretical Chemistry Institute, University of Wisconsin, Madison, WI, 2001); http://www.chem.wisc.edu/ nbo5.

6. (a) Paddon-Row, M. N.; Wu, Y.-D.; Houk, K. N. J. Am. Chem. Soc. 1992, 114, 10638. (b) Wu, Y.-D.; Tucker, J. A.; Houk, K. N. J. Am. Chem. Soc. 1991, 113, 5018. (c) Wong, S. S.; Paddon-Row, M. N.; J. Chem. Soc., Chem. Commun. 1991, 327.

7. (a) Yadav, V. K.; Ganesh Babu, K.; Balamurugan, R. Tetrahedron Lett. 2003, 44, 6617. (b) Yadav, V. K.; Balamurugan, R. J. Org. Chem. 2002, 67, 587.

8. (a) Ganguly, B.; Chandrasekhar, J.; Khan, F. A.; Mehta, G. J. Org. Chem. 1993, 58, 1734. (b) Mehta, G.; Singh, S. R.; Priyakumar, U. D.; Sastry, G. N. Tetrahedron Lett. 2003, 44, 3101 .

9. Our extensive experience with the use of different cations (e.g., $\mathrm{H}^{+}, \mathrm{Li}^{+}, \mathrm{Na}^{+}$) in the application of the cation complexation model has demonstrated that it is often cost-effective to use $\mathrm{H}^{+}$. The employment of a any other cation does not change the result.

10. Hahn, J. M.; le Noble, W. J. J. Am. Chem. Soc. 1992, 114, 1916.

11. The authors are thankful to a referee for this suggestion. 